\title{
Trace data visualisation enquiry: a methodological coupling for studying information practices in relation to information systems
}

Trace data visualisation enquiry

\author{
Björn Ekström \\ Swedish School of Library and Information Science, Borås, Sweden
}

\begin{abstract}
Purpose - The purpose of this paper is to examine whether and how a methodological coupling of visualisations of trace data and interview methods can be utilised for information practices studies.

Design/methodology/approach - Trace data visualisation enquiry is suggested as the coupling of visualising exported data from an information system and using these visualisations as basis for interview guides and elicitation in information practices research. The methodology is illustrated and applied through a small-scale empirical study of a citizen science project.

Findings - The study found that trace data visualisation enquiry enabled fine-grained investigations of temporal aspects of information practices and to compare and explore temporal and geographical aspects of practices. Moreover, the methodology made possible inquiries for understanding information practices through trace data that were discussed through elicitation with participants. The study also found that it can aid a researcher of gaining a simultaneous overarching and close picture of information practices, which can lead to theoretical and methodological implications for information practices research.

Originality/value - Trace data visualisation enquiry extends current methods for investigating information practices as it enables focus to be placed on the traces of practices as recorded through interactions with information systems and study participants' accounts of activities.
\end{abstract}

Keywords Practice-based studies, Sociomateriality, Trace ethnography, Interview methods, Visual methods, Methodology, Information practices, Citizen science, Elicitation

Paper type Research paper

\section{Introduction}

Society is becoming ever more datafied as mundane activities are made into machinereadable data (van Es and Schäfer, 2017). Peoples' interactions with technical systems and infrastructures such as search engines, social media, online education and citizen science platforms are no exception - these systems collect and generate data about their users and individual activities that collectively can be analysed as traces of practices, so called trace data (Geiger and Ribes, 2011, p. 1). The notion of big data has spawned a rise in research seeking to make sense of these traces using mostly quantitative methods. For a qualitatively inclined researcher interested in how practices, denoting sets of routinised actions, shared ways of understanding the world, rules, norms, conventions and material and geographical settings (Pilerot and Lindberg, 2018) unfold, trace data can be used to recreate these activities.

(C) Björn Ekström. Published by Emerald Publishing Limited. This article is published under the Creative Commons Attribution (CC BY 4.0) licence. Anyone may reproduce, distribute, translate and create derivative works of this article (for both commercial and noncommercial purposes), subject to full attribution to the original publication and authors. The full terms of this licence may be seen at http:// creativecommons.org/licences/by/4.0/legalcode

The author would like to thank the participants of the study for their time and effort. The author would also like to thank the Information Practices and Digital Cultures research group and his supervisors Professor Ola Pilerot and Senior Lecturer Veronica Johansson at the University of Borås for valuable feedback.

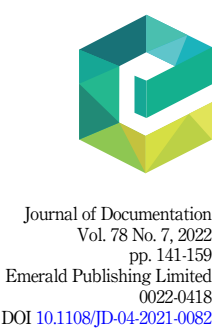


JD

78,7

142

In the investigation of information practices as observations, annotations, photographing, verifying, editing and listing, trace data are particularly useful for investigating such interactions in relation to information systems.

However, while commonly used computational methods for exploring trace data using quantitatively oriented methods undeniably provide helpful ways of wrangling and analysing data, the sense-making of the meanings of the results would also benefit from qualitative approaches and inclusions of first-person interpretations. In order to present results that are explained as meaningful practices, consideration needs to be taken to the participants enacting the practices and the situated settings through which they occur. Interview methods give at hand a plausible way to derive such explanations. However, studies of information practices in relation to information systems would benefit from simultaneously keeping focus on the trace data from the information systems to investigate the doings that have occurred in connection to the systems. In order to accomplish a first-person validated stance to the study of information practices in relation to information systems, a coupling of research methods is desirable.

The aim of this study is to examine whether and how a methodological coupling of geographical visualisations of trace data and interview methods, henceforth trace data visualisation enquiry, can be utilised for information practices studies. Even though the paper primarily should be regarded as a methodological contribution, it also contains a brief report from a small-scale empirical study of a citizen science project, which is used as an illustration of the methodological line of reasoning. The aim is fulfilled by addressing the following research questions:

$R Q 1$. How can trace data visualisation enquiry be beneficial to current approaches in citizen science?

RQ2. How can trace data visualisation enquiry be utilised in information practices research?

RQ3. What are the theoretical implications of trace data visualisation enquiry for information practices research?

This paper is structured as follows: After this introduction, a literature review on methods in information practices research is presented, with a certain focus on semi-structured interviews, trace ethnography and visual elicitation. Next, the methodology of trace data visualisation enquiry is presented. This is followed by a section in which trace data visualisation enquiry is put to work in a small-scale empirical study of information practices in a citizen science project. The paper ends with a concluding discussion on the methodology's contributions to citizen science research, its usefulness for information practices research and its theoretical implications for information practices research.

\section{Selective literature review: previous methods used in information practices research on information systems}

A recurring theme in practice-oriented library and information science research, commonly termed information practices, is how information is handled in relation to information systems and infrastructures (Borgman, 2007; Bowker et al., 2009; Huvila, 2019). More specifically, this line of research is engaged with the study of how information is sought, shared, produced and organised. Various types of methodological approaches have been adopted for such studies; interview methods and document studies, participatory observation (Pilerot et al., 2017) as well as trace ethnography (e.g. Mugar et al., 2015), focus groups (Lloyd et al., 2013) and visual elicitation methods (Hicks and Lloyd, 2018). In this section, I will discuss how semi-structured interviews, trace ethnography and visual elicitation in particular have been used in information practices research. The ambition is not to provide a full-fledged overview of all and each method in this area. Rather, I strive to make visible what three prominent methods have to offer, and what they do not offer, for the study of information practices. 


\section{Interview studies}

Semi-structured interviews have been widely used as a method for investigating information practices in a variety of settings (e.g. Haider and Sundin, 2019; Lloyd et al., 2013; McKenzie, 2003; Pilerot and Limberg, 2011). Semi-structured interviews have also been combined with other qualitative research methods, for example document studies and participant observations (Pilerot, 2014) and focus groups (Lloyd et al., 2013). Advantages of the semi-structured interview method include that it provides generous statements about participants' experiences (Newell et al.,2016). Theoretical underpinnings on how to investigate practices are also noted, where it is suggested that the interviewees' sayings can offer access to bundles of practices (Pilerot, 2016). Exploratory studies incorporating semi-structured interviews as a research method have noted that sample sizes of interviewees tend to be relatively small, leading to a lack of broadly generalisable conclusions (Newell et al., 2016). Other, related critique includes that interviews mainly give control to the researcher rather than the participant, which in turn can give rise to uneven power relations between the two parties (Johansson, 2012). Combinations of methods, such as adding document analysis to semi-structured interviews in the methodological repertoire (Pilerot, 2016), have been presented as one way to mitigate these issues.

When investigating information practices in technology-fuelled settings, the semistructured interview can provide examinations of practices through steering the data collection and subsequent analysis to subjective accounts of practices. Foci can be placed on activities commonly linked, drawing the attention to how routines, norms and conventions are enacted. One important point concerning information systems is that automatically generated traces are formed as people interact with them, which can be beneficial for retroactively studying practices. Such traces are however also being studied in information practices research and related subfields, which is explicated in the next section.

\section{Trace ethnography}

There is currently a growing tendency in practice-oriented library and information science research to incorporate traces from information systems as empirical data for ethnographyoriented studies (e.g. Sköld, 2018; Sawyer et al., 2012; Tattersall Wallin and Nolin, 2020; Østerlund et al., 2015). This methodological approach is generally called trace ethnography. Trace ethnography serves to seize documentary traces created in systems, such as version histories, transaction logs and conversation transcripts, for the reconstruction of interactions with these systems. This enables the researcher to "[...] carefully follow coordination practices, information flows, situated routines, and other social and organizational phenomena across a variety of scales" (Geiger and Ribes, 2011, p. 1). Trace ethnography is also linked to the notion of digital methods, as "[...] techniques for the study of societal change and cultural condition with online data" (Rogers, 2019, p. 3).

For information practices studies adopting a trace ethnographic approach, traces have been studied as virtual participations (Sköld, 2018) and as renderings of reading practices over time (Tattersall Wallin and Nolin, 2020) through means of data visualisation. Other studies apply a mixed-methods approach to investigations of trace data, for instance through combinations of trace ethnography with interviews and participant observation (Jackson et al., 2018; Mugar et al., 2015; Sawyer et al., 2012) or by collecting social media posts coupled with screenshots and field notes (Graminius and Haider, 2018).

By adopting trace ethnography as a research method, practices are studied in hindsight by putting together bits and pieces of trace data to form narratives of people's engagement with information systems. Such assemblages of disparate data points lead to a methodological perspective through which automatically generated metadata of varying sorts are explored retroactively from a third person perspective in order to understand activities which have been carried out in relation to information systems. The perspective
Trace data visualisation enquiry 
$\mathrm{JD}$

78,7

144

strives for an objective approach in the sense that practices are investigated from a viewpoint seeking to investigate how they have been carried out. However, the point of view is fixed to a historic perspective that provides a distance to the participants enacting the practices.

A certain setting which has been under scrutiny using a mixed-methods approach for the last years is that of citizen science; scientific projects which incorporate non-scientists in the research process (Citizen Science Association, 2019). Such studies combine trace ethnography with interviews and participant observation (Jackson et al., 2018) or incorporating participant observation, interviews and trace ethnography (Mugar et al., 2015). Current methodological proposals (e.g. Østerlund et al., 2020, p. 14) suggest that "visualizations of trace data [. . .] can serve as productive interview prompts". Combining methods is hence a plausible approach for studying participants' information practices in information systems, making use of trace ethnographic approaches and also inquiring participants about their traces through elicitation. Such a pairing has previously been suggested for inquiring about visualisations of trace data in general and applied to the field of political communication (Dubois and Ford, 2015). However, for understanding distributed handling of information in contemporary research settings, the methodology needs further development in relation to contemporary visual methods and to information practices research. This leads to the following section of the literature overview, which concerns visual elicitation.

\section{Visual methods}

Visual methods are research methods used to include graphics, such as paintings, drawings, photographs or diagrams, for the production and representation of knowledge (Jupp, 2006) in data collection settings. Moreover, visual, or graphic, elicitation can provide contributions in interview settings which are more or less unreachable through other types of enquiry. By referring to visual sources, an improved communication between participants and researchers is possible which in turn "can lead researchers to improved conceptualizations of a domain and provide a strong foundation upon which to base future theorizing activities" (Crilly et al., 2006, p. 20). This include understanding notions of interpretations of the visualisations, the accuracy of what is depicted and, perhaps most importantly, "offer their perspectives on the subject in general, as the sources prompts reflection on topics not previously discussed" (Crilly et al., 2006, p. 21).

An overview article depicts several visual elicitation methods in information practices research (Hicks and Lloyd, 2018). These include graphic elicitation in order to investigate participant understandings of information concepts (Brier and Lebbin, 2015), mapping through participant-created drawings of diagrams and timelines (Savolainen and Kari, 2004) and photo elicitations through photographs taken by study participants (Buck, 2016). Visual methods such as the incorporation of video in information practices work are deemed important for examining participatory practices as visualisations can provide tools for researching seeing and understanding (Jupp, 2006). However, the method has also been noted to mainly be used in a broader package of methods (Jupp, 2006).

One approach for researching understandings of visualisations from a critical perspective has been done by combining interviews with participant observation in terms of a type of contextual enquiry (Johansson, 2012). In this particular contextual enquiry approach, observations enable a way to witness participants conducting their work, where following interviews functions as a way to direct attention to the participants' notions of their work. These two methods are then critically examined by directing the enquiry and interpreting the findings from a distance (Johansson, 2012).

In a datafied society, it is possible to engage with trace data from information systems and generate visualisations based on interactions. As positivist approaches treats trace data as objective empirical data without problematizing materiality and social practices forming them, there is a need for complementary approaches to understanding these data. For the last decade, 
a growing tendency in information visualisation research is the emphasis on the social usage and online networks of data sets (Sluijs, 2008). Moreover, participatory visual and digital methods have been suggested to "produce rich multimodal and narrative data guided by participant interests and priorities, putting the methods literally in hands of the participants themselves" (Gubrium and Harper, 2016, p. 13). This allows access to social research knowledge travelling beyond the academy (Gubrium and Harper, 2016). Whether used as a basis for developing interview guides or as material for elicitation methods, visualisations can be utilised in information practices research to interconnect the subjective, present features of accounts gained from the semi-structured interview and the more distanced, non-participant and retroactive provisions of trace ethnography. While graphics have been used in information practices research (Brier and Lebbin, 2015; Buck, 2016; Savolainen and Kari, 2004), visualisations from trace data remains to be investigated as ground for interview methods in order to study how the data have come to be from a sociomaterial perspective, and what information practices have led to these becomings. This issue fuels a need for complementary approaches, which is further explored in the following section where trace data visualisation enquiry is presented as a suggested methodological approach.

\section{Trace data visualisation enquiry - a suggested new approach}

I will begin this section by framing the suggested methodology through practice theory. From a practice-theoretical perspective, practices are "embodied, materially mediated arrays of human activity centrally organized around shared practical understanding” (Schatzki, 2001, p. 11). More specifically, the suggested trace data visualisation enquiry approach adopts a theoretical perspective grounded in the metaphor of zooming in and out of practice (Nicolini, 2009). This approach provides a way to understand "the connection between the here-and-now of the situated practicing and the elsewhere-and-then of other practices" (Nicolini, 2009, p. 1392). Moreover, it entails "zooming in on the real-time practising as an organized set of doings and sayings carried out using a variety of tools and mediatory resources" (Nicolini, 2009, p. 1400). The perspective hence adopts a relational understanding to practices, where the local can be seen in the global, and vice versa (Nicolini, 2017). The practices under scrutiny are also viewed from a zooming out perspective by following connections in action (Nicolini, 2009). This is performed by understanding practices as "providing an appreciation of the connectedness of practice and the fact that activities never happen in isolation, so that practices are always immersed in a thick texture of interconnections" (Nicolini, 2009, p. 1407).

\section{Trace data visualisation enquiry}

Trace data visualisation enquiry extends methods in information practices research by placing weight both on the traces of interactions in relation to information systems and participants' accounts of their activities. It originates in studying traces of information practices from information systems as doings. These doings are then visualised and transferred to interview guides, used in elicitation methods and problematised through sayings. In order to grasp the situatedness of information practices in information systems, both the doings as retroactive studies of automatically generated traces and sayings as participants' explanations of the circumstances are significant units of analysis. As information systems systematically generate trace data of user interactions, traces can provide valuable insights into information practices as they can function as starting points for interview studies regarding how people interact with information.

Large-scale, collaborative information systems such as social media, search engines and citizen science portals generally include the possibility of exporting interaction histories. Such data constitute the main empirical material for trace ethnographic research (Geiger and Ribes, 2011). The longer the information system has been available and populated by

Trace data visualisation enquiry 
JD

78,7

146

participants, the more data there are to access. Visual methods can aid the exploration of larger exported data sets from these information systems. In the suggested trace data visualisation enquiry approach, visualisations are adopted to provide insights from how information practices have been enacted. Trace data often contain indication of time, dates and geographical locations. Visualising these aspects can contribute to an understanding of what, when and where information practices have occurred. As such, the suggested method adopts perspectives in other trace interview methods (e.g. Dubois and Ford, 2015) and extending these by focussing specifically on aspects of practices such as routines, shared understandings, rules, locations and material objects (Pilerot and Lindberg, 2018).

By analysing and interpreting patterns of visualised traces, interviews can complement the analytical process. Visualisations can, in this, sense be used as a point of departure for specific and detailed questions in the interview setting, facilitating detailed investigations of situated information practices grounded in the trace data. Moreover, visualisations can also be used as a direct elicitation material through which a dialogical conversation is taking place through mutual interpretation and sense-making (Jupp, 2006). A coupling of the two approaches to the interview setting is also possible, where certain aspects of the trace visualisations are inquired through questions and others are commonly discussed by elicitation. By so doing, a defamiliarizing effect is attained as the participants sees themselves and their past, mundane activities through the visualised trace data; the participants form a distance to their own activities, being able to confer about how they acted not only in a firstperson but also in third-person perspective. These courses of action provide space for the participants in line with previous participatory approaches (e.g. Jackson et al., 2018; Johansson, 2012; Pilerot, 2014), enabling the researcher to be co-present with the participants in a practice-theoretical sense through being in the loop with their doings without necessarily being co-located on site (Beaulieu, 2010; Geiger and Ribes, 2011). The methodology therefore attains an investigative approach in which the participants are provided the opportunity to reflect upon their pursuits while at the same time might fill in the blanks where visualisations might prove difficult to provide full exposure of activities.

The main difference from other types of mixed-methods approaches coupling interview methods with trace ethnography is that trace data visualisation enquiry place larger weight on the juxtaposition of spatiality and temporality. Trace data visualisation enquiry could be used to give rise to investigations of how people engage with and through information systems in relation to their surroundings, especially as the situatedness of practices is becoming mediated by technologic applications and devices. Through trace data visualisation enquiry, the researcher can be provided with desirable insights of participants' localised doings from the trace data. These insights can facilitate the understanding of the situatedness of information practices in the setting through sayings occurring in interviews. Participants can also be assisted in speaking about past activities by seeing their practices visualised, which can function as memory support and enable involvement in interpretation and knowledge production. Trace data visualisation enquiry is hence an abductive methodological approach (cf. Brinkmann, 2015), where the information practices researcher works back and forth with the data.

\section{Trace data visualisation enquiry put to work}

In this section, trace data visualisation enquiry is put to work through a small-scale empirical study for illustrative and evaluative purposes. First, the empirical case is introduced. Second, an investigation of temporal aspects through the here and now and the elsewhere-and-then is presented. Third, a comparison of temporal and geographical aspects of practices is introduced. Fourth, an exploration of inquiring about metadata for seeing the distributed in the local is represented. 


\section{Introducing the empirical case}

The empirical setting for the application of the suggested approach is Fingerprints of change: Abisko plants and phenology, a scientific project at the Climate Impacts Research Centre (CIRC), Umeå University, Sweden. The aim of Fingerprints of change is to "[collect] species distributions and phenology data for the Abisko region (focused in and around Abisko National Park)" (Larson et al., 2018). As such, it is part of a larger research effort to identify plants' responses to climate change in an arctic region. Citizen science, the involvement of non-scientists in scientific research (Citizen Science Association, 2019), is adopted as a scientific process. The technical citizen science platform iNaturalist with its supplementary smartphone applications is central for the collective knowledge production of species observations. These factors taken together make Fingerprints of change a suitable case to illustrate trace data visualisation enquiry.

Participants for the study were selected based on the following criteria: They had made use of the iNaturalist platform, they had made species observations in the Abisko region in northern Sweden and they had made species observations that had been incorporated into the citizen science project. Four individuals were recruited as participants for the study.

\section{Data collection}

Trace data generated by the participants, each observations' species name, taxon classes, observer, date, quality grade, place, geographical coordinates and annotations, were exported in comma-separated value (CSV) format using iNaturalist's export tool (iNaturalist, n.d.) on 7 September 2020.

Semi-structured interviews were conducted with the four participants. These interviews served to derive explanations, accounts and statements providing an in-depth reflection upon the information practices within the chosen setting. A transformative interview process was adopted, striving to utilise the interview in a dialogic way (Brinkmann, 2015). The interviews were conducted in a part semi-structured, part elicitation-based (Smith et al., 2012) manner using screen-sharing technology where discussions about the geographical visualisations were held. The interviews were recorded in audio and video format and subsequently transcribed. Interview lengths ranged from approximately 45-75 min.

Because of the distributed nature of citizen science projects, and that the participants were distributed in Germany and England, interviews were conducted through a video conference application between 13 and 20 November 2020. Three interviews were conducted, where two of the participants were interviewed at the same occasion.

\section{Analysis}

For the purpose of visualising the exported data set, an application was developed for geographic information systems analysis of trace data (see Figure 1). The application was built using the programming language $\mathrm{R}$, making use of data science software packages, amongst others, shiny (Chang et al., 2020), leaflet (Cheng et al., 2019) and tidyverse (Wickham et al., 2019). The application provided geographical, spatiotemporal visualisations of trace data that were used as material for analysing and interpreting information practices from a spatiotemporal perspective. Data were filtered to a selection of the four individuals chosen as participants for the study.

As interview guides were aligned with the visualisations, the interview transcripts were analysed in par with the visualisations. Foci were placed both on the sayings from the interviews and the doings visualised from the trace data to explore these data in light of each other. This gave at hand a reciprocal understanding of small and large phenomena by shifting focus in a gliding sense, leading to a nuanced analysis of the empirical data.

Trace data visualisation enquiry 
$\mathrm{JD}$

78,7

148

Figure 1.

iNaturalist species observation mapper (iNSOM)

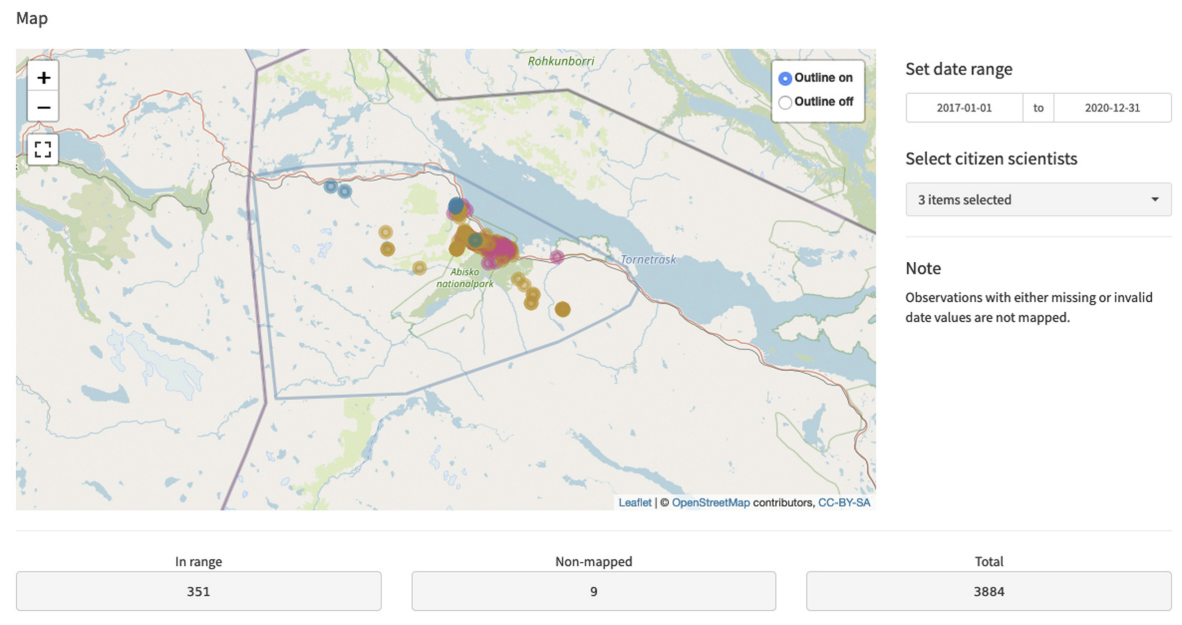

The analysis was thus performed abductively (Brinkmann, 2015), seeking to analytically move between the theoretical approach and the data.

\section{Ethics}

The exported data set consisted of open data. As some observations had their coordinates obscured, either for reasons relating to protected species or for user privacy, they were subsequently omitted from the exported data set. The four participants were respectively pseudonymised as Alex, Charlotte, Emma and Victoria. Information about the study and forms of consent were distributed and collected before interviews were conducted.

\section{Investigating time through the here and now and the elsewhere-and-then}

As an initial adaptation of trace data visualisation enquiry to the empirical data, investigations of how citizen science information practices unfold through the here and now and the elsewhere-and-then, with an emphasis on temporal changes, were made. In order to do so, iNSOM was filtered to only show Emma's data production, which seemingly are few in numbers (see Figure 2). As the trace data shows, Emma (the blue dots) has been producing small numbers of data during the year of 2020. The points are scattered over one region and have been conducted during the same year.

By investigating traces of past activities with their detailed time and date stamps, insights of when information practices unfolded were gained. The visualisation does however leave questions of the comprehensiveness of the activities that makes up the practices. In other words, while visualisations provided insights to where and when practices were enacted, they revolved to a lesser extent to understandings of how and why practices had been carried out. These insights could however be transferred to the semi-structured interviews, with the purpose of providing means for zooming in on the practices through first-person validated understandings of how practices actually had been carried out within the provided time frame.

Gaining participant-generated insights on the basis of visualisations was facilitated by asking how one activity related to other practices in an elsewhere-and-then manner (cf. Nicolini, 2009). Inquiring Emma about her participation in the project showed that the visualisations depicted the research data which she uploaded to iNaturalist, but not a full view of the practices. As Figure 2 shows, Emma has mainly been identifying species through 


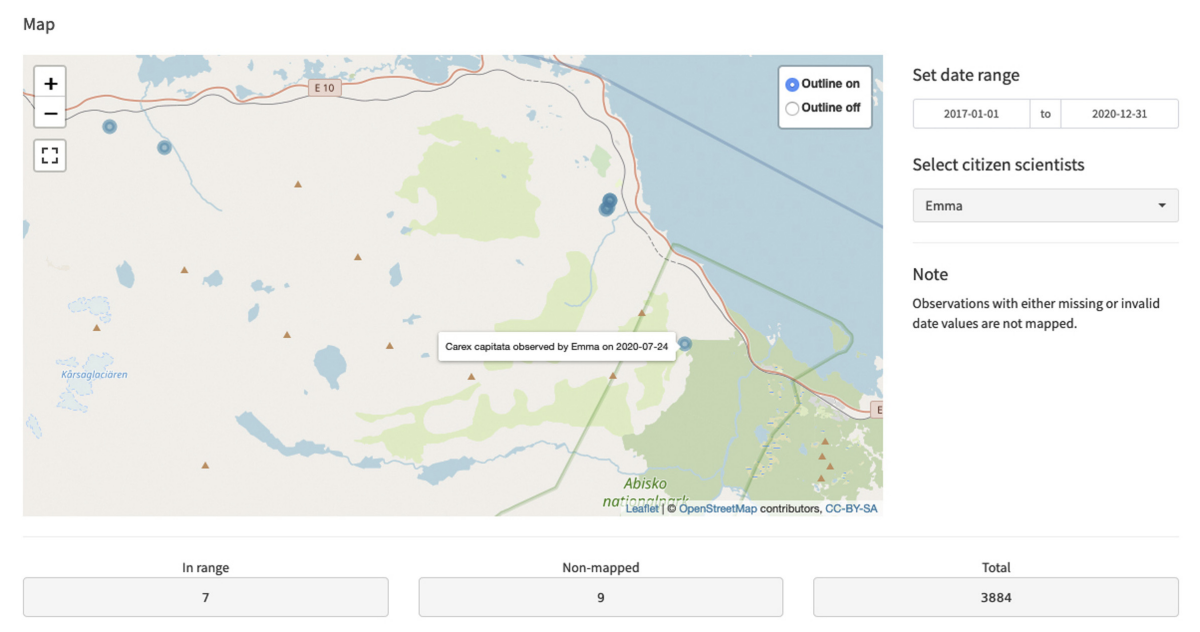

Trace data visualisation enquiry

the iNaturalist application during 2020. However, during the interview, Emma mentioned how she actually has been active in the Fingerprints of change project since 2017. Though it was not until 2020 when she began using iNaturalist to conduct species observations, mainly because she was lacking an adequate smartphone for identification purposes up to that date. Emma also mentioned how she during her 2020 stay in Abisko worked partly with the Fingerprints of change project and partly with another research study. In other words, her contributions to other research projects also meant implicitly producing citizen science data for the Fingerprints of change project. As such, there was a reciprocal relationship between these projects and the practices they encompass.

Visualisations provided retroactive, distanced insights into when activity had been carried out, which were further investigated through the interviews. While this did not provide investigations into the here and now of practices as they occurred in real time, it did give an indication into how the here and now had occurred, which prompted additional investigations into how engagement in Fingerprints of change was connected to other research-related practices. Inquiring participants about mapped trace data formed a point of discussion around practices, which facilitated the interview setting by providing the interviewer with valuable prior knowledge about information practices before interviews were conducted.

Trace data visualisation enquiry thus provided understandings of temporal modalities of information practices in citizen science projects. While Figure 2 indicates how data production had been occurring over time during one year by visualising data points as a retroactive here and now activity (cf. Nicolini, 2009), the semi-structured interview gave rise to how the understandings of the data production were to be understood in line with related practices. This gave at hand the suggested methodology invoking an abductive understanding to information practices. Visualisations indicating situated patterns (Geiger and Ribes, 2011) were coupled with subjective, rich experience from participants (Newell et al., 2016) through a performative interview setting (Brinkmann, 2015).

\section{Coupling temporal and geographical aspects of practices}

In the prior subsection, temporality was addressed regarding activity over time and used as a basis for the interview questions. In what follows, the temporal aspect is further investigated by also incorporating geographical aspects in the suggested approach. This was done in 
$\mathrm{JD}$

78,7

150

Figure 3.

Charlotte's data production during 2018 order to further explore how visualisations could guide the interview process and how this influenced a transformative interview setting (Brinkmann, 2015).

The juxtaposition of the sayings and the doings assisted the coupling of temporal and spatial modalities in information practices. The trace data were mapped using geographical visualisation techniques and further filtered with regard to time and date stamps. This in turn provided visualisations where both changes in space and over time were traceable, providing material for the investigation of information practices. By investigating clusters of activity, as well as single data points as detours, it was possible to distinguish where activities had been occurring en masse and where there were blank spots. This enabled a way to initially understand routinised activity with regard to locations in a practice theoretical vein (e.g. Pilerot and Lindberg, 2018). As initial investigations of routinised and situated activity had been occurring through geographical and time-wise plots, these were additionally unfolded through inquiries. In other words, the inquiries of subjective accounts made it possible to delve into the routines, seeking to understand the reason behind them by focussing on rules, norms, conventions and their material arrangements.

By comparing annual data production, this analytical procedure was exemplified with the participant pseudonymised as Charlotte who had been producing data for the Fingerprints of change project between 2017 and 2019. As an illustration of temporal change identified from the visualisations, the contributions made in 2018 and 2019 were compared and retroactively zoomed in (cf. Nicolini, 2009). Figure 3 represents Charlotte's data production at a transect (a path in which plant occurrences are counted) up to Mount Nuolja in Abisko National Park during 2018. As is deducible from the visualisation, Charlotte did however not produce any data at the peak of the mountain during 2018. The data production at a transect during this year was primarily done halfway up the mountain, with a detour to the Aurora Sky Station seen at the cluster to the south of a transect. During 2019, however, data points were traced further up the mountain. As made visible in Figure 4, data production activities were also performed at Mount Nuolja's peak. This indicated a geographical shift in where species observations occurred as years went by.

When inquired about the species observations located on the path to Mount Nuolja, Charlotte described how her range on the mountain shifted upwards over the course of years. Identification work began at the foot of the mountain and continued by gradually moving up the mountain during 2019. Charlotte also distinguished that the observation process

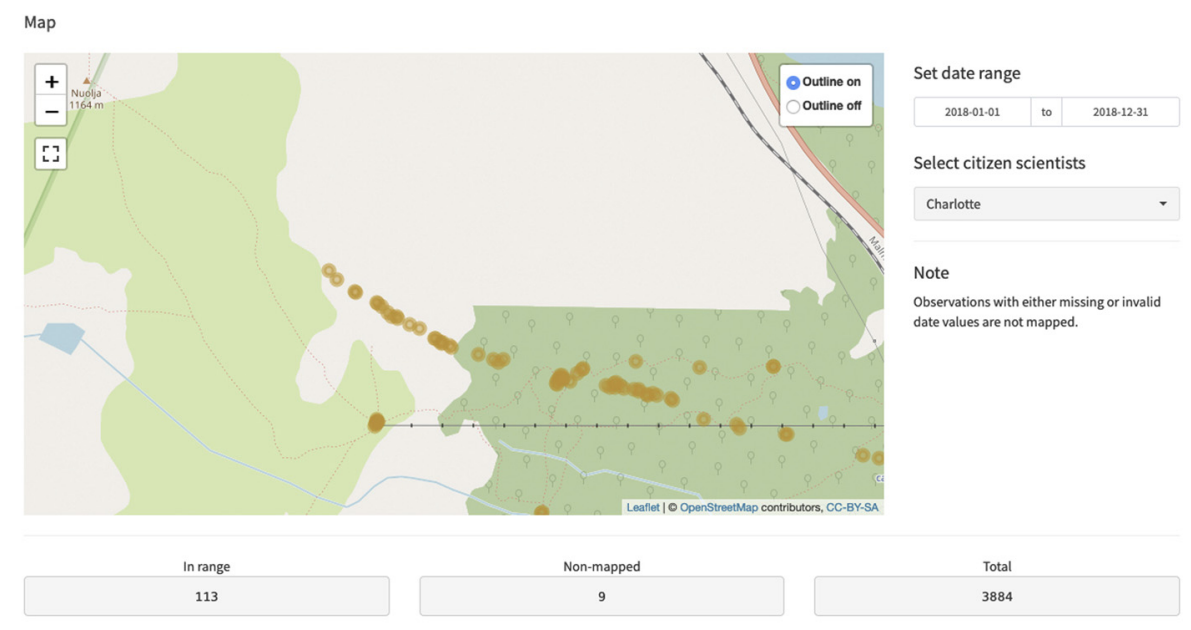




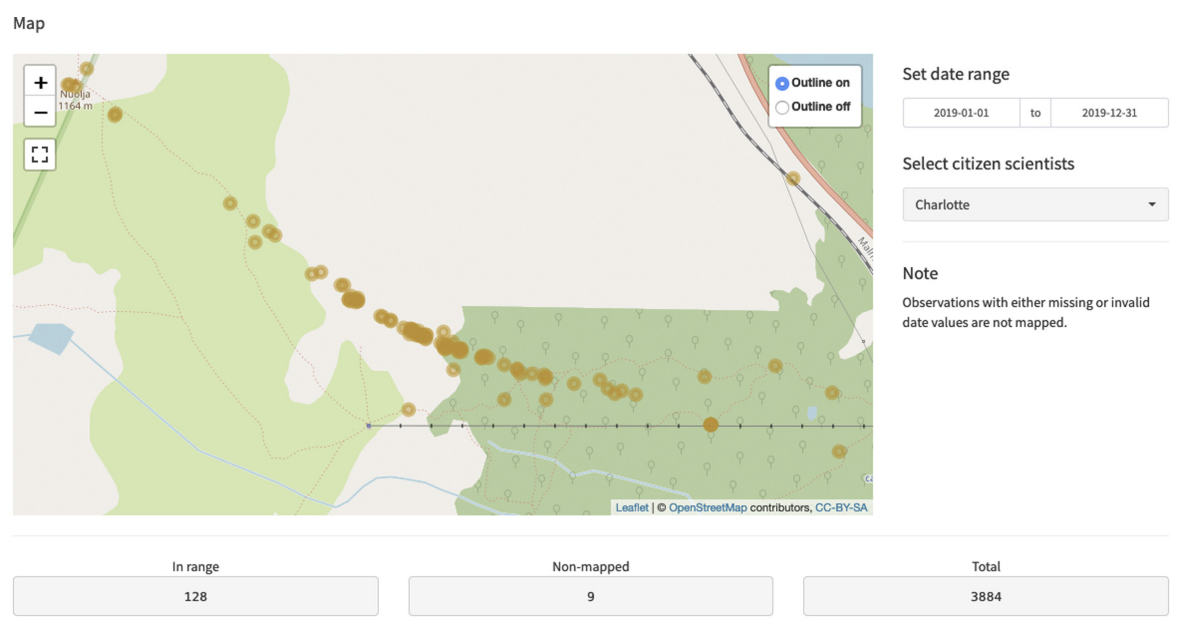

Trace data visualisation enquiry

151

increased in difficulty by elevation; many species on the top of the mountain were more difficult for her to identify. The mentioned accounts altogether showed how her practices changed as knowledge and experience was formed over the years, which comprised results not possible to be distinguished by simply analysing the trace data. These sayings thus provided more thorough explanations to the visualisations, whereby a juxtaposition between the two years was possible from a zooming out point of view (cf. Nicolini, 2009).

As prior methodological proposals (e.g. Østerlund et al., 2020) have suggested investigating, trace data visualisation enquiry found that the use of visualisations as interview prompts was suitable as a practice-oriented research method on citizen science. It was also found that a similar beneficial relationship could be seen the other way around, that is, how the interviews could be utilised for the understanding of the visualisations. Altogether, the different strands of the suggested approach contributed to a multifaceted understanding of data production in citizen science, with a double focus on time-wise and geographic aspects.

\section{Inquiring about metadata for seeing the global in the local}

In this subsection, I delve into the metadata and show how it can be used as a basis for understanding information practices in citizen science. More concretely, this is done by invoking metadata to see the global in the local, i.e. how small-scale information practices are immersed in large-scale information practices (cf. Nicolini, 2017) and vice versa.

Trace data derived from information systems can be varied in scope but have in common that they represent fine-grained, detailed metadata of past activity. By delving into these precise, divided traces of activities, it was possible to distinguish local information practices as they had been produced in a certain situated setting, at a given time and location. Joining several data points together hence led to a zoomed-in notion of an activity. In turn, this coupling was utilised as a centralised unit from which the interview setting emerged. Localised practices could hence be discussed, seeking to gain elaborate understandings of how they were tied together with other practices such as the ambition to provide verifiable and correct research data. In what follows, documentation practices and ambitions of providing verifiable data are further depicted through a discussion of how visualisations of metadata were used as a theme discussed in the interview setting. 
$\mathrm{JD}$

78,7

152

By returning to the geographical perspective, metadata about a specific species observation were made visible through a pop-up box. The plant observed on 17 June 2019, as seen in Figure 5, is a Vaccinium uliginosum, a plant commonly found together with blueberries. The description reads "Around post 47 of transect", indicating the observation's geographical location at a narrow point. Metadata also provided certain other indications of the type of species observed such as the observations' common name, taxon class and the date and place in which it was observed. The observation is marked research grade, which means that it has been verified communally by other users and is hence validated as accepted research data.

For understanding how information practices occurred in the citizen science project, it was not necessarily the details per se which were of interest but rather the level of which the details were specified. When asking Victoria and Alex about the validity of observations, they acknowledged that developing photography and annotation skills was of high importance for collaboration when producing valid research data in the Fingerprints of change project. This provided a way for other citizen scientists' abilities to confirm or edit species identifications collaboratively. The eye for details, they noted, is especially of importance for participants who are not botanists by education and hence do not have expertise in plant identification by eyesight. In order to do so, however, other participants with more experience would be able to provide information on the correct species. Victoria and Alex further depicted the gradual understanding how to preserve details when making observations:

Victoria: "The more we used [the iNaturalist smartphone application], the more we realised how clear the photos you have to take."

Alex: Yeah, certain parts of the plants as well. It'd be useful if you could get maybe three or four different photos of the leaves, the flower buds and a lot of different parts of it. So that someone could look at it and be like 'okay, this is the one plant' and look at the different aspects of the plant to ID it better."

Victoria: "Yeah, especially before they bloomed because there's a lot of willow, say, on Mount Nuolja and [laughter] trying to identify that before it bloomed without the leaves was hard [. . . ] really hard work. So you did have to look at how the branches come out and the colour of the branches and the length. So you had to sort of take as many identifying shots as you possibly could if you wanted a positive ID."

Figure 5.

Zoom-in view of a transect up to Mount Abisko, with a metadata popup view for one species observation

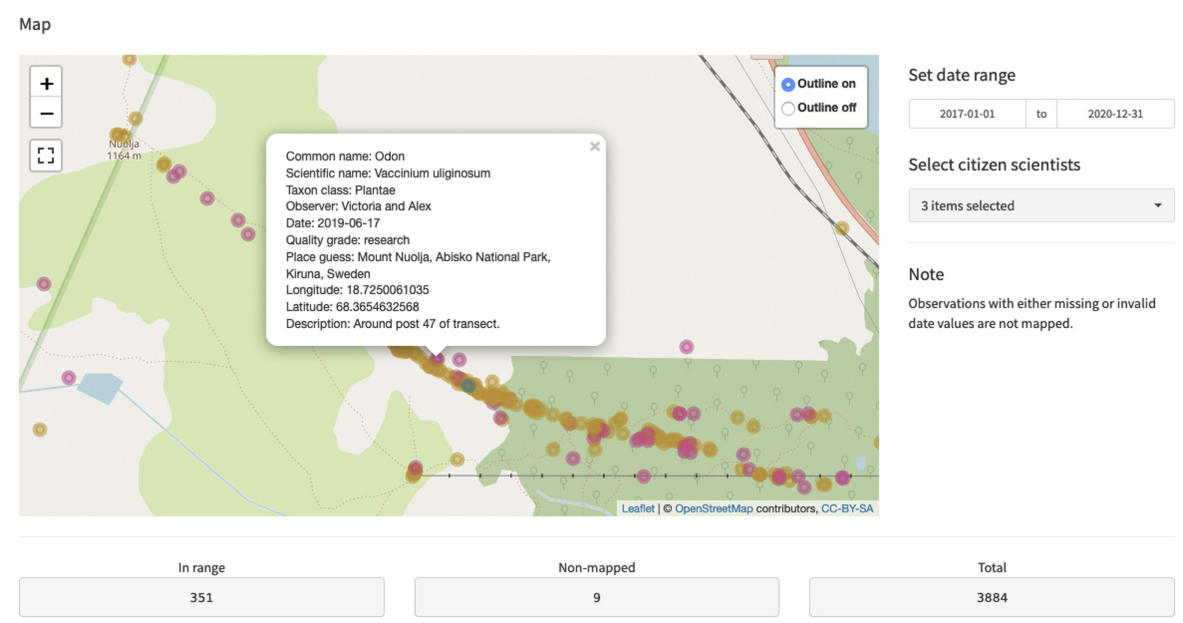


The transcript above shows the necessity of quality and quantity of photographs for the assurance of validity in data production in citizen science projects. As Alex and Victoria explained, the understanding of both photographic details and number of photographs of different parts of observed species grew through continued engagement in the project. A detailed photograph was deemed significant in order to make sense of the observed plant. As Victoria stated in the last quoted paragraph, the geographical conditions also affected the data production practices as identifying species before blooming necessitated an eye for details in fieldwork. Furthermore, photographing various parts of the species in detail was necessary for other people to be able to confirm the correct identity in the future. In other words, the local practices in the citizen science project had implications for the data quality of the project as a whole; the overarching purposes of the project reciprocally provided ground for the information practices as they happened through on-site field work. Trace data visualisation enquiry accomplished this result by focussing on initial analyses performed through findings from the metadata, which were subsequently transferred to the interview setting. Seeing the local in the global, how small acts of ensuring validity in species observations contributed to the quality of the data set at large, was hence a perspective that could gain citizen science research, which trace data visualisation enquiry served to reach.

\section{Concluding discussion}

In this section, I will discuss the findings by addressing the research questions. First, I explain how trace data visualisation enquiry can be used to explore citizen science information practices. Second, I show how trace data visualisation enquiry can be utilised in information practices research. Third, I provide an answer to what theoretical implications trace data visualisation enquiry can have for information practices research.

\section{Contributions to citizen science research}

Prior methodological proposals suggest that visualisations of trace data can serve as bases for interview guides (Østerlund et al., 2020), which can be beneficial for the study of citizen science. Trace data visualisation enquiry enables seizing trace data from citizen science projects for the use as points of departure in interview studies. By visualising the trace data in advance of interview settings, early insights into the information practices of study participants can be gained, which can assist the researcher in getting nearer the participants already before interviews have taken place; it is possible, so to say, to speak the same language by letting the participants become aware of one's knowledge about the subject. This leads to early establishment of a close relationship between the interviewer and the interviewee, facilitating the dialogic interview in a way which might be difficult to accomplish otherwise. Since citizen science projects often are scattered with multitudes of participants at different geographical places, trace data visualisation enquiry can contribute to establish co-presence in interview settings which do not occur face to face (Beaulieu, 2010). As such, trace data visualisation enquiry can bridge the geographical distance of interviews performed through phone or video conference calls. The geographical dispersion would be increasingly significant to bear in mind in future studies incorporating a larger set of participants.

Gaining early insights into participants' practices and inquiring participants can also lead to new layers of understanding of the visualisations. This is exemplified in the case of Emma who, when being asked about her engagement in the project, explained that her activity preceded what the data points in the visualisation showed. By making use of the trace data from the trace ethnographic perspective (e.g. Geiger and Ribes, 2011), it was possible to investigate to what extent participation had been carried out. However, the adoption of a trace data visualisation enquiry approach provided a closer exploration of when, but also how,
Trace data visualisation enquiry 
$\mathrm{JD}$

78,7

154

data production occurred. Both elements of the approach hence facilitated each other in terms of the ability to move between positions in the empirical data. In other words, when working back and forth between the two, it became possible to problematise the temporal aspect of data production in citizen science. The approach also enabled the understanding of why only certain traces of data production were made visible and at the same time resulted in understandings of how Emma's participation was tied to other activities in a relational practice-oriented way (cf. Nicolini, 2017, 2009). This enabled an exploration of the participants' information practices, which can facilitate future work on other situated practices in citizen science.

Trace data visualisation enquiry also enables the researcher to achieve a simultaneous overarching and close picture of citizen science activities. By using visualisations as bases for interviews, the researcher can gain a topological understanding of previous activities, which can be more thoroughly investigated in the interview settings, as in the case of Charlotte (Figures 3 and 4). However, visualisations can also provide more detailed investigations, which the interviews can explain in a more overarching sense; investigating the trace data enables analyses of social aspects of information systems and data sets (Sluijs, 2008). This is visible in the case of Victoria and Alex (Figure 5), where annotations are thoroughly explored. Asking the participants about these annotations, understandings regarding the role of details in annotation practices were gained. Inquiring the participants about a single instance of documentation led to investigations of the significance of good practice for data longevity in the project. This finding shows the significance of trace data visualisation enquiry in the sense that visualisations comprise a close examination of an instanced, local activity which the interview broadened, also contributing to a zooming-out view of how the activity is enacted in relation to related activities (cf. Nicolini, 2017, 2009). In this regard, trace data visualisation enquiry can contribute to citizen science studies on motivations for involvement. What the method does not allow in this form, however, are real-time observations of participant activity in the same vein that participant observation does. A way to resolve this issue could be to engage in participant observation, or incorporate interviews taking place through video calls, while participants are conducting field work or documenting observations.

\section{Adaptability for other strands of information practices research}

In the following, I discuss the methodology's adaptability for the study of information practices, thereby providing an answer to the second research question.

Trace data visualisation enquiry was utilised to uniformly analyse information practices in citizen science research. Future-wise, research on other types of scholarly communities could be facilitated by the methodological approach suggested in this paper. Semi-structured interviews, document studies and participant observation have been widely adopted in studies of scholarly information practices (Fry, 2006; Pilerot, 2014, 2015, 2016). By gaining access to the traces of scholars' information practices through for instance logs in file hosting services, it is possible to understand scholarly work by focussing on file transmissions and edits. These annotation practices can be visualised in terms of temporal keyword occurrence plots or modelled as diagrams, which in turn can be used as elicitation material for the dialogical study of how cooperation occurs in scholarly work. Another possibility would be to investigate scholarly networks on social media through webometric visualisations such as network graphs (e.g. Gunnarsson Lorentzen, 2020; Vainio and Holmberg, 2017) or heat maps (Nelhans and Gunnarsson Lorentzen, 2016). For gaining passage to a research field, it is noted that "[e]ach person entering the discursive complexes of a scientific field must learn to cope with those communicative means and processes that mediate participation with others" (Bazerman, 1997, p. 305). In empirical settings of scholarly character, trace data visualisation enquiry can offer such an entry point by being in tandem with the participants whose 
information practices are being explored. However, gaining entry to trace data, in cases where open data are not possible to attain, might provide data collection limitations. Moreover, it is crucial for the researcher to attain ethical consent when adapting trace data visualisation enquiry.

It would also be possible to adapt trace data visualisation enquiry to other empirical settings where data from large-scale information systems form the unit of analysis. Semistructured interviews have proven successful to explore information practices through largescale web search engines (e.g. Haider and Sundin, 2019). Adopting a reciprocal methodological approach by invoking traces as empirical data could lead to a further understanding of information practices in relation to web search systems; through user interfaces or through smart devices. Traces of information practices can generally be exported by single users from these systems. The collection of such data, however, necessitates inquiries from single participants to perform manual exports from their own accounts, as data are otherwise irretrievable due to privacy concerns. Visualisations possible to derive from this type of data include topic modelling graphs or keyword-based line plots. The trace data in visualised form can then be paired with interview methods and utilised in the transformative interview process (Brinkmann, 2015). This in turn can provide a multifaceted methodological approach to investigating everyday information seeking through web search engines. For example, this would be possible through comparing, and inquiring about, search queries made during certain periods of time and through various types of media (web-browser interfaces, smart devices, voice assistants), continuing ethnographic studies of infrastructures (Star, 1999).

Moreover, the suggested methodological approach could be adapted to information literacy research settings. While public cloud services have been understood to incorporate digital surveillance acts (Lindh and Nolin, 2016), automatically generated data could be used to also trace classroom activities in order to understand information practices and literacies in educational settings. While this would necessitate a problematisation of the educational platforms and the data that are generated and transferred from them, the trace data could nevertheless be adopted as a basis to understand pupils' and students' engagement in these platforms, including digital literacy (e.g. Polizzi, 2020). Of certain importance here, however, are aspects of information ethics, as outlined in previous research. For instance, data collection should be conducted in consent with, and with permission from, participants (Rubel and Jones, 2016). Similar ethical considerations should be attained in trace ethnography studies in general and in relation to studies in educational settings in particular. Employing trace ethnography perspectives to information literacy studies could lead to nuanced methodologies for research on datafied educational technology as infrastructures for learning. Even still, adapting the method necessitates careful ethical considerations to both visualised trace data and participant sayings, while also justifying data collection through specific criteria (Rubel and Jones, 2016).

\section{Theoretical implications for information practices research}

In this final subsection, I discuss the theoretical implications that trace data visualisation enquiry have for information practices research.

Practice-oriented research is concerned with analysing how sayings and doings lay foundations of practices through unmasking routines, rules, norms, conventions, material arrangements and locations (Nicolini, 2009; Pilerot and Lindberg, 2018; Schatzki, 2012). As for the everyday routinised activity and the implicit rules, norms and conventions through which practices are enacted, trace data visualisation enquiry enables fine-grained investigations of separate small-scale activities, which altogether lets the researcher investigate detailed, mundane parts of information practices. When these atomised traces of everyday activities
Trace data visualisation enquiry 
JD

78,7

become visualised and subsequently inquired about, the methodology allows for a simultaneous close and distant investigation of the mundane; the closeness being attained by focussing on single data entries and their relation to the other activities, and the distance explained through the participants' reflections upon how the bundle of activities are tied together. In other words, datafied representations of mundane activities (van Es and Schäfer, 2017) are being investigated from the inside out. This points towards a relational understanding of routines, rules, norms and conventions (Nicolini, 2017) to be further investigated in information practices research.

Furthermore, as mentioned above, localisation and situatedness play a certain role in unfolding routinised activity as these invoke manners of interacting with information in a given setting. The trace data visualisation enquiry approach to studying information practices enables a way to explain the sensibilities of the location through sayings which point towards detailed explanations of how environmental settings might enable and constrain certain activities. When pairing such explanations with visualisations of trace data points through geographical coordinates, it becomes possible, for example, to add another layer of meaning-making to the locations. Routines can hence be investigated through spatial visualisations. While practice theory seeks to understand "the connection between the hereand-now of the situated practicing and the elsewhere-and-then of other practices" (Nicolini, 2009, p. 1392), a question that arises is what makes up the here, and what makes up the elsewhere. Practice theoretical studies are occupied with investigating action where the action is. However, one has to ask oneself what this where is. The notion of location in information practices would hence need further exploration, which trace data visualisation enquiry can serve to achieve.

Finally, studies of information practices in relation to information systems are engaged with a certain focus on materiality (Pilerot, 2014; Pilerot and Lindberg, 2018). By unpacking the traces of practices through trace data visualisation enquiry, it is possible to achieve finegrained understandings of how applications and technical tools have been used. These finegrained understandings provide a simultaneous close and distant analysis of the materiality of metadata, gaining a point of departure in the enactment of documentation, observation, annotation and photographing in research settings. While this has to some extent been done in prior contributions to information practices research (Sköld, 2018), trace data visualisation enquiry can contribute to further unmasking the digital bits and pieces that represent traces of information practices.

\section{References}

Bazerman, C. (1997), "Discursively structured activities”, Mind, Culture, and Activity, Routledge, Vol. 4 No. 4, pp. 296-308.

Beaulieu, A. (2010), "Research note: from Co-location to Co-presence: shifts in the use of ethnography for the study of knowledge", Social Studies of Science, Vol. 40 No. 3, pp. 453-470.

Borgman, C.L. (2007), Scholarship in the Digital Age: Information, Infrastructure, and the Internet, MIT Press, Cambridge.

Bowker, G.C., Baker, K., Millerand, F. and Ribes, D. (2009), "Toward information infrastructure studies: ways of knowing in a networked environment", in Hunsinger, J., Klastrup, L. and Allen, M. (Eds), International Handbook of Internet Research, Springer Netherlands, Dordrecht, pp. 97-117.

Brier, D.J. and Lebbin, V.K. (2015), "Learning information literacy through drawing”, in Joan Petit, Ms. and T, M.S. (Eds), Reference Services Review, Emerald Group Publishing No. 1, Vol. 43, pp. $45-67$.

Brinkmann, S. (2015), InterViews: Learning the Craft of Qualitative Research Interviewing, 3rd ed., Sage Publications, Los Angeles, LA. 
Buck, S. (2016), "In their own voices: study habits of distance education students", Journal of Library and Information Services in Distance Learning, Routledge, Vol. 10 Nos 3-4, pp. 137-173.

Chang, W., Cheng, J., Allaire, J., Xie, Y. and McPherson, J. (2020), Shiny: Web Application Framework for R, Manual, available at: https://cran.r-project.org/web/packages/shiny/index.html.

Cheng, J., Karambelkar, B. and Xie, Y. (2019), Leaflet: Create Interactive Web Maps with the JavaScript, 'Leaflet' Library, Manual, available at: https:/cran.r-project.org/web/packages/leaflet/index.html.

Citizen Science Association (2019), "Citizen science: partnering the public and professional scientists", Citizen Science Association, available at: https://www.citizenscience.org/.

Crilly, N., Blackwell, A.F. and Clarkson, P.J. (2006), "Graphic elicitation: using research diagrams as interview stimuli”, Qualitative Research, Vol. 6 No. 3, pp. 341-366.

Dubois, E. and Ford, H. (2015), "Trace interviews: an actor-centered approach", International Journal of Communication, Vol. 9, p. 25.

Fry, J. (2006), "Scholarly research and information practices: a domain analytic approach", Information Processing and Management, Vol. 42 No. 1, pp. 299-316.

Geiger, R.S. and Ribes, D. (2011), "Trace ethnography: following coordination through documentary practices", System Sciences (HICSS), 2011 44th Hawaii International Conference on System Sciences, IEEE, pp. 1-10.

Graminius, C. and Haider, J. (2018), "Air pollution online: everyday environmental information on the social media site Sina Weibo", Journal of Documentation, Vol. 74 No. 4, pp. 722-740.

Gubrium, A. and Harper, K. (2016), Participatory Visual and Digital Methods, Routledge, London, New York.

Gunnarsson Lorentzen, D. (2020), "Bridging polarised Twitter discussions: the interactions of the users in the middle", Aslib Journal of Information Management, Vol. 73 No. 2.

Haider, J. and Sundin, O. (2019), Invisible Search and Online Search Engines: the Ubiquity of Search in Everyday Life, Routledge, Milton Park, Abingdon, Oxon.

Hicks, A. and Lloyd, A. (2018), "Seeing information: visual methods as entry points to information practices", Journal of Librarianship and Information Science, Vol. 50 No. 3, pp. 229-238.

Huvila, I. (2019), "Learning to work between information infrastructures", Information Research, Vol. 24 No. 2, available at: http://InformationR.net/ir/24-2/paper819.html (Archived by WebCite ${ }^{\circledR}$ at http://www.webcitation.org/78mnTEFK7).

iNaturalist (n.d), Export Observations iNaturalist, iNaturalist, available at: https://www.inaturalist.org/ observations/export.

Jackson, C., Crowston, K., Østerlund, C. and Harandi, M. (2018), "Folksonomies to support coordination and coordination of folksonomies", Computer Supported Cooperative Work (CSCW), Vol. 27 No. 3, pp. 647-678.

Johansson, V. (2012), "A time and place for everything?: social visualisation tools and critical literacies", Doctoral thesis, Högskolan i Borås, Akademin för bibliotek, information, pedagogik och IT, Borås.

Jupp, V. (2006), "Visual methods", The SAGE Dictionary of Social Research Methods, SAGE Publications London. doi: 10.4135/9780857020116.n222.

Larson, K.W., MacDougall, A., Olofsson, J., Baird, E., Gill, R. and Johansson, J. (2018), "Fingerprints of change: abisko plants and phenology", Climate Impacts Research Centre, available at: https:// www.arcticcirc.net/our-projects/abisko-plants-and-phenology.

Lindh, M. and Nolin, J. (2016), "Information we collect: surveillance and privacy in the implementation of google apps for education”, European Educational Research Journal, SAGE Publications, Vol. 15 No. 6, pp. 644-663.

Lloyd, A., Keenan, M.A., Thompson, K.M. and Qayyum, A. (2013), "Connecting with new information landscapes: information literacy practices of refugees", Journal of Documentation, Vol. 69 No. 1, pp. 121-144.

Trace data visualisation enquiry 
McKenzie, P.J. (2003), "A model of information practices in accounts of everyday-life information seeking”, Journal of Documentation, Vol. 59 No. 1, pp. 19-40.

Mugar, G., Østerlund, C., Jackson, C.B. and Crowston, K. (2015), Being Present in Online Communities: Learning in Citizen Science, ACM Press, New York, pp. 129-138.

Nelhans, G. and Gunnarsson Lorentzen, D. (2016), "Twitter conversation patterns related to research papers", Information Research, Vol. 21 No. 2, available at: http://nformationR.net/ir/21-2/SM2. $\mathrm{html}$ (Archived by WebCite® at http://www.webcitation.org/6hn1QAh41).

Newell, B.C., Gomez, R. and Guajardo, V.E. (2016), "Information seeking, technology use, and vulnerability among migrants at the United States-Mexico border", The Information Society, Routledge, Vol. 32 No. 3, pp. 176-191.

Nicolini, D. (2009), "Zooming in and out: studying practices by switching theoretical lenses and trailing connections", Organization Studies, Vol. 30, doi: 10.1177/0170840609349875.

Nicolini, D. (2017), 'Is small the only beautiful? Making sense of 'large phenomena' from a practicebased perspective", in Hui, A., Schatzki, T.R. and Shove, E. (Eds), The Nexus of Practices: Connections, Constellations and Practitioners, Routledge, London.

Østerlund, C., Snyder, J., Sawyer, S., Sharma, S. and Willis, M. (2015), "Documenting work: from participant observation to participant tracing", in Elsbach, K.D. and Kramer, R. (Eds), Handbook of Qualitative Organizational Research: Innovative Pathways and Methods, Routledge, New York, NY, Vol. 2015.

Østerlund, C., Crowston, K. and Jackson, C. (2020), "Building an apparatus: refractive, reflective, and diffractive readings of trace data", Journal of the Association for Information Systems, Vol. 21 No. 1, doi: 10.17705/1jais.00590.

Pilerot, O. (2014), "Making design researchers' information sharing visible through material objects", Journal of the Association for Information Science and Technology, Vol. 65 No. 10, pp. 2006-2016.

Pilerot, O. (2015), "Information sharing in the field of design research", Information Research, Vol. 20 No. 1, available at: http://www.informationr.net/ir/20-1/isic2/isic26.html.

Pilerot, O. (2016), "A practice-based exploration of the enactment of information literacy among $\mathrm{PhD}$ students in an interdisciplinary research field", Journal of Documentation, Emerald Group Publishing, Vol. 72 No. 3, pp. 414-434.

Pilerot, O. and Limberg, L. (2011), "Information sharing as a means to reach collective understanding: a study of design scholars' information practices", Journal of Documentation, Emerald Group Publishing, Vol. 67 No. 2, pp. 312-333.

Pilerot, O. and Lindberg, J. (2018), "Inside the library: academic librarians' knowing in practice", Journal of Librarianship and Information Science, Vol. 50 No. 3, pp. 254-263.

Pilerot, O., Hammarfelt, B. and Moring, C. (2017), "The many faces of practice theory in library and information studies", Information Research, Vol. 22 No. 1, available at: http://InformationR.net/ ir/22-1/colis/colis1602.html (Archived by WebCite ${ }^{\circledR}$ at http://www.webcitation.org/6oJcNV0JJ).

Polizzi, G. (2020), "Digital literacy and the national curriculum for England: learning from how the experts engage with and evaluate online content", Computers and Education, Vol. 152, pp. 1-20.

Rogers, R. (2019), Doing Digital Methods, Sage, London.

Rubel, A. and Jones, K.M.L. (2016), "Student privacy in learning analytics: an information ethics perspective", The Information Society, Vol. 32 No. 2, pp. 143-159.

Savolainen, R. and Kari, J. (2004), "Placing the Internet in information source horizons. A study of information seeking by Internet users in the context of self-development", Library and Information Science Research, Vol. 26 No. 4, pp. 415-433.

Sawyer, S., Kaziunas, E. and Øesterlund, C. (2012), "Social scientists and cyberinfrastructure: insights from a document perspective", Proceedings of the ACM 2012 Conference on Computer Supported Cooperative Work, Association for Computing Machinery, New York, NY, USA, pp. 931-934. 
Schatzki, T.R. (2001), "Introduction: practice theory", in Schatzki, T.R., Von Savigny, E. and Knorr Cetina, K. (Eds), The Practice Turn in Contemporary Theory, Routledge.

Schatzki, T.R. (2012), "A primer on practices: theory and research”, in Higgs, J., Barnett, R., Billett, S., Hutchings, M. and Trede, F. (Eds), Practice-Based Education: Perspectives and Strategies, Sense Publishers, Rotterdam, pp. 13-26.

Sköld, O. (2018), Documenting Videogame Communities: A Study of Community Production of Information in Social-Media Environments and its Implications for Videogame Preservation, universitet, Humanistisk-samhällsvetenskapliga vetenskapsområdet, Historisk-filosofiska fakulteten, Institutionen för ABM, Uppsala universitet, Uppsala, Uppsala, available at: http:// urn.kb.se/resolve?urn= urn:nbn:se:uu:diva-336748.

Sluijs, J.P. (2008), “Sense.Us: towards a more social 'social visualization”, First Monday, Vol. 13 No. 12, doi: $10.5210 / \mathrm{fm} . v 13 i 12.2306$.

Smith, P.D., Emmison, M. and Mayall, M. (2012), Researching the Visual, Sage Publications, Thousand Oaks, California, CA, Vol. 2.

Star, S.L. (1999), "The ethnography of infrastructure", American Behavioral Scientist, Vol. 43 No. 3, pp. 377-391.

Tattersall Wallin, E. and Nolin, J. (2020), "Time to read: exploring the timespaces of subscriptionbased audiobooks", New Media and Society, Vol. 22 No. 3, pp. 470-488.

Vainio, J. and Holmberg, K. (2017), "Highly tweeted science articles: who tweets them? An analysis of Twitter user profile descriptions", Scientometrics, Vol. 112 No. 1, pp. 345-366.

van Es, K. and Schäfer, M.T. (2017), The Datafied Society. Studying Culture through Data, Amsterdam University Press, Amsterdam, doi: 10.5117/9789462981362.

Wickham, H., Averick, M., Bryan, J., Chang, W., McGowan, L.D., François, R., Grolemund, G., Hayes, A., Henry, L., Hester, J., Kuhn, M., Lin Pedersen, T., Miller, E., Milton Bache, S., Müller, K., Ooms, J., Robinson, D., Paige Seidel, D., Spinu, V., Takahashi, K., Vaughan, D., Wilke, C., Woo, K. and Yutani, H. (2019), "Welcome to the tidyverse", Journal of Open Source Software, Vol. 4 No. 43, p. 1686.

\section{About the author}

Björn Ekström is a doctoral student in Library and Information Science at the Swedish School of Library and Information Science, University of Borås, Sweden. His main research interests include information practices, citizen science and digital methods. Björn Ekström can be contacted at: bjorn.ekstrom@hb.se
Trace data visualisation enquiry

For instructions on how to order reprints of this article, please visit our website:

www.emeraldgrouppublishing.com/licensing/reprints.htm

Or contact us for further details: permissions@emeraldinsight.com 